\title{
Article \\ Study on the Microstructure and Spectra of Regrown Quartz Crystals from Chinese Jewelry Market
}

\author{
Danyi Zhou ${ }^{1, *} \mathbb{C}$, Taijin Lu ${ }^{1}$, Huiru Dai ${ }^{2}$, Jieran $\mathrm{Lv}^{2}$, Shouming Chen ${ }^{3}$, Zhonghua Song ${ }^{1}\left(\mathbb{D}\right.$ and Jian Zhang ${ }^{1}$ \\ 1 Beijing Institute of Gemology, National Gems \& Jewelry Technology Administrative Center, Ministry of \\ Natural Resources, Beijing 100013, China; lutj@ngtc.com.cn (T.L.); songzh@ngtc.com.cn (Z.S.); \\ zhangj@ngtc.com.cn (J.Z.) \\ 2 Beijing Lab, National Gemstone Testing Center, Beijing 100013, China; lvjieran@126.com (J.L.) \\ 3 Institute of Geology, Chinese Academy of Geological Science, Beijing 100037, China; csm@cags.ac.cn \\ * Correspondence: zhoudy@ngtc.com.cn
}

Citation: Zhou, D.; Lu, T.; Dai, H.; Lv, J.; Chen, S.; Song, Z.; Zhang, J. Study on the Microstructure and Spectra of Regrown Quartz Crystals from Chinese Jewelry Market. Crystals 2021, 11, 1145. https://doi.org/ $10.3390 /$ cryst11091145

Academic Editors: Alessandra Toncelli and Zhaohui Li

Received: 22 August 2021

Accepted: 15 September 2021

Published: 19 September 2021

Publisher's Note: MDPI stays neutral with regard to jurisdictional claims in published maps and institutional affiliations.

Copyright: (C) 2021 by the authors Licensee MDPI, Basel, Switzerland. This article is an open access article distributed under the terms and conditions of the Creative Commons Attribution (CC BY) license (https:// creativecommons.org/licenses/by/ $4.0 /)$

\begin{abstract}
Regrown quartz crystals consist of the natural section and the synthetic section grown by hydrothermal technique, which has become popular on the Chinese jewelry market in recent years. Similar gemological properties to those of natural quartz have brought challenges to gem identification and also new questions to scientific research. In this study, microstructure and spectral characteristics of the two sections of regrown quartz crystals were investigated by three dimensional computed tomography system and infrared spectroscopy. Results showed that the natural section has a higher porosity and there are also many micron- to millimeter-sized pores on the interface of the two sections. Different infrared absorption peaks of the two sections at the $3300-3600 \mathrm{~cm}^{-1}$ range were mainly attributed to the different existence state of $\mathrm{OH}$ groups. The distinction of microstructure and spectral characteristics between the natural and synthetic sections indicate their different growth condition. Compared with natural quartz, a relatively stable growth environment during the synthetic process leads to a lower porosity and the alkali growth solution could result in the change of the existence state of $\mathrm{OH}$ groups in the regrown quartz crystals.
\end{abstract}

Keywords: quartz; crystals; regrown; microstructure; spectra

\section{Introduction}

Quartz, also called 'rock crystal', is widely distributed on the earth and has broad application in many industries. High-quality quartz with various colors can be regarded as a gemstone and has a high share on the jewelry market. In addition, quartz can also be used as piezoelectric material and optical material, which require high clarity. Different types and amounts of impurities are common in natural quartz. Therefore, clear quartz is often synthesized by hydrothermal synthetic technique in the industry. This technique simulates the crystallization process of natural quartz in the hydrothermal fluid. It can be dated back to the 19th century and has been continuously improved ever since. The market demand also accelerated the development of this synthetic technique [1-10]. Nowadays, different kinds of colorless or various color quartz can be synthesized by the hydrothermal method.

In recent years, regrown quartz crystal druse has sprung up and become popular on the Chinese jewelry market, which is produced by regrowing a layer of synthetic quartz on the surface of natural quartz. Due to similar appearance and inclusion characteristics, it has brought some difficulties to laboratory identification, and investigation of its properties can help understand the regrowth process. Previous studies mainly focused on the surface topography, inclusions feature and optical property of such regrown quartz crystals [11,12]. However, the microstructure and spectral characteristics of its different sections (natural section and synthetic section) still need to be investigated, which can reveal more information on the structure, component, and formation condition during the regrowth process. In this study, regrown quartz crystal samples were collected from the Donghai crystal market 
(Donghai, Jiangsu province, China), which is the largest trade center of rock crystal (quartz) in China. Combined with the survey of synthetic quartz factories, microstructure and spectral characteristics were analyzed and their genesis was discussed. Three dimensional (3D) computed tomography system and its artificial intelligence recognition function of visual imaging were used to display the 3D image of the microstructure characteristics of regrown quartz crystals. Spectral characteristics were obtained by infrared spectroscopy. Related results can provide more scientific evidence not only for the regrown quartz crystal identification but also the discussion on the crystal nucleation, growth, and dissolution process of hydrothermally synthetic gemstones on the natural ones.

\section{Materials and Methods}

Two typical regrown quartz crystal druses collected from Donghai crystal market (Donghai, Jiangsu Province, China) (Figure 1). Each druse sample had 10 20 single crystals and six single crystal samples $(\mathrm{Q}-1-1 \sim \mathrm{Q}-1-3, \mathrm{Q}-2-1 \sim \mathrm{Q}-2-3)$ were separated from regrown quartz crystal druses for observation and measurements.

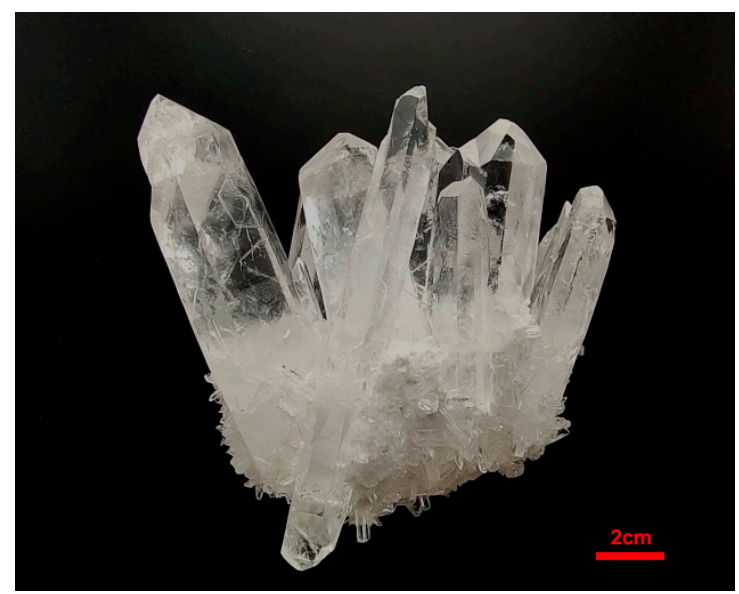

(a)

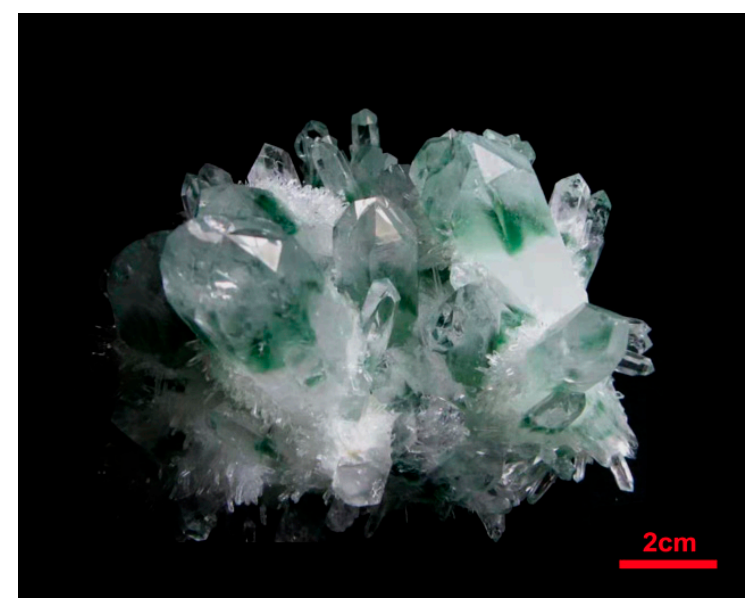

(b)

Figure 1. Investigated regrown quartz crystal druse samples Q-1 (a) and Q-2 (b).

As to the basic gemological properties, the refractive index (RI) of polished samples was measured with a refractometer using diiodimethane as refractive oil. The specific gravity (SG) was obtained by the hydrostatic weighing method. The hardness was determined by the Mohs hardness tester. Their fluorescence was observed by ultraviolet light with main wavelengths of 365 and $254 \mathrm{~nm}$. Chemical composition was analyzed by Thermo Scientific ARL Quant'X energy dispersive X-ray Fluorescence Spectrometer with an operating voltage of $16 \mathrm{kV}$ and a working current of $1.98 \mathrm{~mA}$. Internal inclusion features were observed under ZEISS Stemi 2000-C microscope with the max magnification of $50 \times$.

Microstructure of regrown quartz crystal samples was observed by three dimensional computed tomography system using Nikon XTH225ST, with $127 \mathrm{kV}$ voltage and $100 \mu \mathrm{A}$ electric current. The 3D images were obtained by VG-Studio Max 3.0 visual imaging software, which can realize artificial intelligence recognition of different microstructure characteristics. Fourier-transform infrared (FTIR) spectra were measured by Thermo Scientific Nicolet is 50 spectrometer with Pike Technologies Beam Condenser ${ }^{\mathrm{TM}}$ in the range of $1000-5000 \mathrm{~cm}^{-1}$, with the uncertainty of $2 \mathrm{~cm}^{-1}$. In order to get more accurate spectra of different sections, single crystal samples were cut into slices with the thickness of $5 \mathrm{~mm}$ and polished. 


\section{Results}

\subsection{Basic Gemological Properties}

The investigated samples are transparent, colorless, or with green tint in some zones. The refractive index ranges from 1.54 to 1.55 . The specific gravity values vary between 2.62 and 2.65. The hardness is 7 (Table 1). All investigated samples mainly consist of $\mathrm{SiO}_{2}$ and other trace elements include $\mathrm{Al}, \mathrm{Mg}, \mathrm{Na}, \mathrm{K}, \mathrm{Ca}$, etc. (Table 2), which also exist in natural quartz. All samples are inert to longwave and shortwave UV radiation. Under the observation of a gem microscope, the regrown quartz crystal also has gas-fluid inclusions which arrange in irregular curved planes extending in various directions, as the internal features of natural quartz (Figure 2). Therefore, the basic gemological properties of regrown quartz crystal show no obvious difference from natural quartz.

Table 1. Basic gemological properties of investigated regrown quartz crystal samples.

\begin{tabular}{ccccccc}
\hline $\begin{array}{c}\text { Sample } \\
\text { Number }\end{array}$ & $\begin{array}{c}\text { Sample Number of } \\
\text { Single Crystals }\end{array}$ & $\begin{array}{c}\text { Refractive } \\
\text { Index }\end{array}$ & $\begin{array}{c}\text { Specific } \\
\text { Gravity }\end{array}$ & $\begin{array}{c}\text { Mohs } \\
\text { Hardness }\end{array}$ & \multicolumn{2}{c}{ Fluorescence } \\
\cline { 6 - 7 } Q-1 & Q-1-1 & 1.54 & 2.64 & 7 & LW & SW \\
& Q-1-2 & 1.55 & 2.62 & 7 & Inert & Inert \\
& Q-1-3 & 1.54 & 2.63 & 7 & Inert & Inert \\
Q-2 & Q-2-1 & 1.55 & 2.63 & 7 & Inert & Inert \\
& Q-2-2 & 1.55 & 2.65 & 7 & Inert & Inert \\
& Q-2-3 & 1.54 & 2.64 & 7 & Inert & Inert \\
\hline
\end{tabular}

Table 2. Chemical composition of investigated regrown quartz crystal samples (wt $\%$ ).

\begin{tabular}{ccccccc}
\hline $\begin{array}{c}\text { Sample Number of } \\
\text { Single Crystals }\end{array}$ & $\mathbf{S i O}_{2}$ & $\mathbf{A l}_{2} \mathbf{O}_{3}$ & $\mathbf{M g O}$ & $\mathbf{N a}_{2} \mathbf{O}$ & $\mathbf{K}_{2} \mathbf{O}$ & $\mathbf{C a O}$ \\
\hline Q-1-1 & 96.30 & 1.73 & 0.74 & 0.96 & 0.06 & 0.01 \\
Q-1-2 & 97.26 & 1.59 & 0.62 & 0.29 & 0.04 & 0.02 \\
Q-1-3 & 96.68 & 1.55 & 0.84 & 0.69 & 0.03 & 0.03 \\
Q-2-1 & 97.31 & 1.58 & 0.52 & 0.45 & 0.04 & 0.03 \\
Q-2-2 & 97.25 & 1.60 & 0.61 & 0.38 & 0.02 & 0.01 \\
Q-2-3 & 97.20 & 1.33 & 0.55 & 0.65 & 0.02 & 0.01 \\
\hline
\end{tabular}

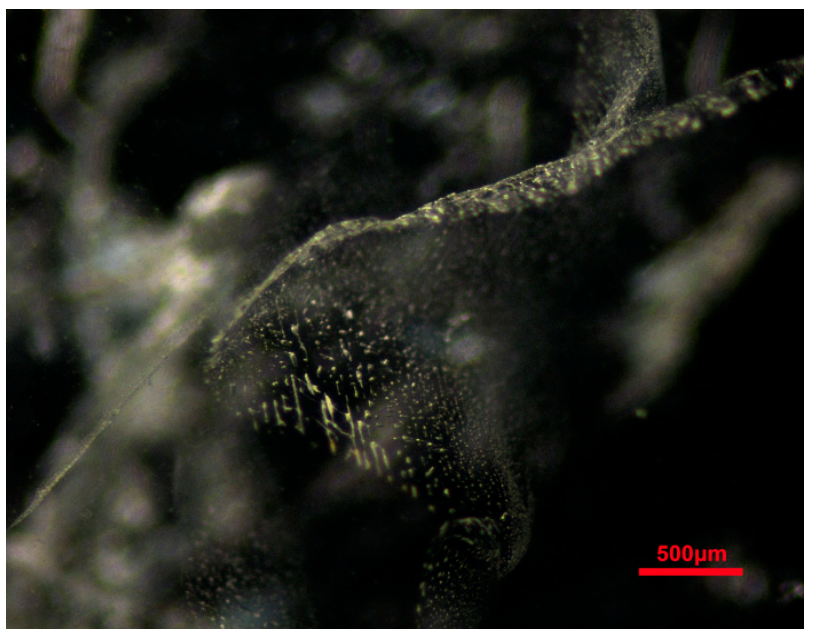

(a)

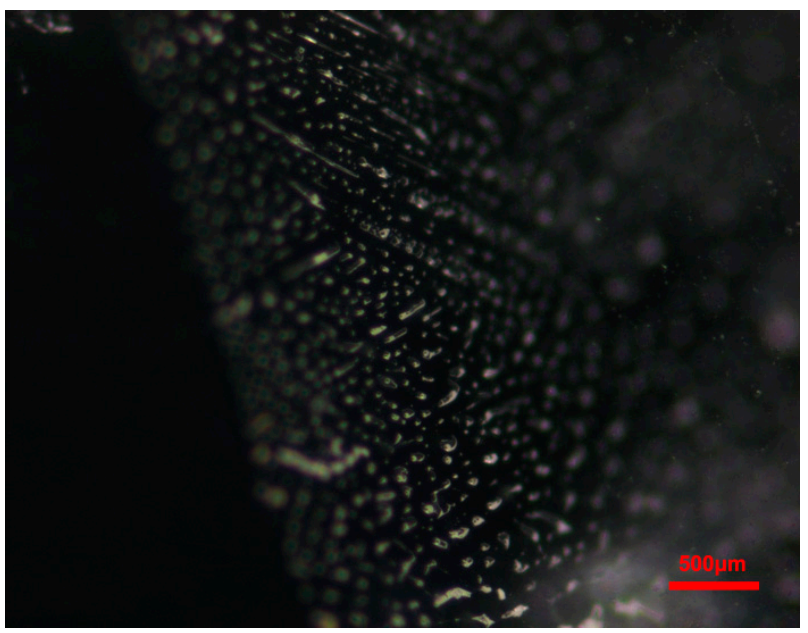

(b)

Figure 2. Typical gas-fluid inclusions in the regrown quartz crystal. 


\subsection{Microstructure Characteristics}

The 3D images of different sections of regrown quartz crystal show different microstructure characteristics, which were obtained by the three dimensional computed tomography system and the intelligence recognition function of visual imaging software. From the side view of the 3D image (Figure 3a), there are many micron- to millimeter-sized pores in the natural section, with the volume from $8 \times 10^{5} \mu \mathrm{m}^{3}$ to $0.17 \mathrm{~mm}^{3}$. However, the regrown section has much lower porosity and rare pores in it, in which the pore volume is under $6 \times 10^{4} \mu \mathrm{m}^{3}$. From the top view of the 3D image (Figure 3b), most pores in investigated samples are distributed along or close to the interface of the two sections. These pores in the regrown quartz crystal can be vacuum or filled with gas, fluid, or gas-liquid phases.

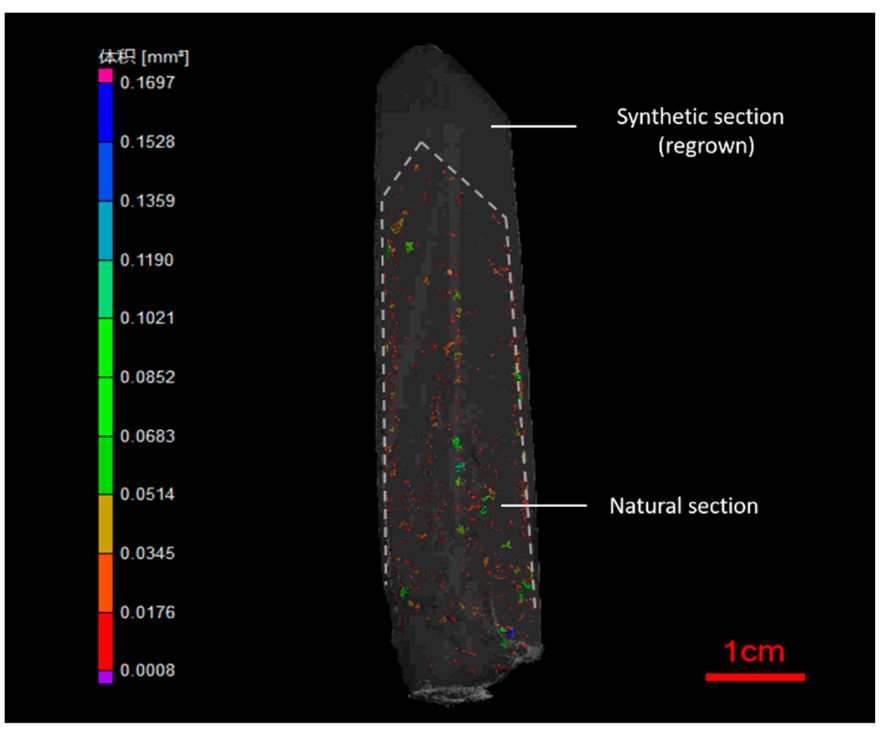

(a)

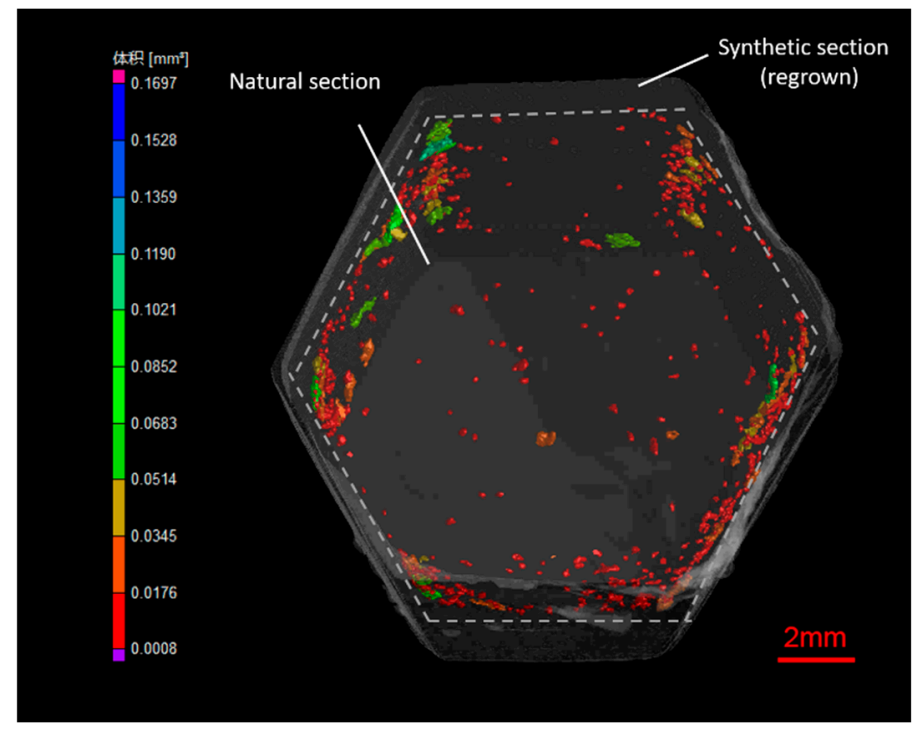

(b)

Figure 3. 3D images of microstructure characteristics of the regrown quartz crystal. (a) Side view image, (b) top view image. (inside the dotted line - the natural section; outside the dotted line- - the synthetic section).

\subsection{Infrared Spectral Characteristics}

The distinction on infrared spectra between the natural section and the synthetic section mainly shows in the regions from 3300 to $3600 \mathrm{~cm}^{-1}$. The natural section shows absorption peaks at 3310,3378 , and $3484 \mathrm{~cm}^{-1}$, while the synthetic section displays obvious absorption at 3400,3440 , and $3585 \mathrm{~cm}^{-1}$ (Figure 4).

Previous studies have shown that the absorption peaks at 3310,3378 , and $3484 \mathrm{~cm}^{-1}$ in the natural quartz are associated with hydroxyl group $(\mathrm{OH})$ in the structure. For synthetic quartz, the different existence state of hydroxyl group is influenced by the alkali cations (mainly $\mathrm{Na}^{+}, \mathrm{K}^{+}, \mathrm{Li}^{+}$) of growth solution, which can result in the absorption at 3400,3440 , and $3585 \mathrm{~cm}^{-1}$ [13-21]. 


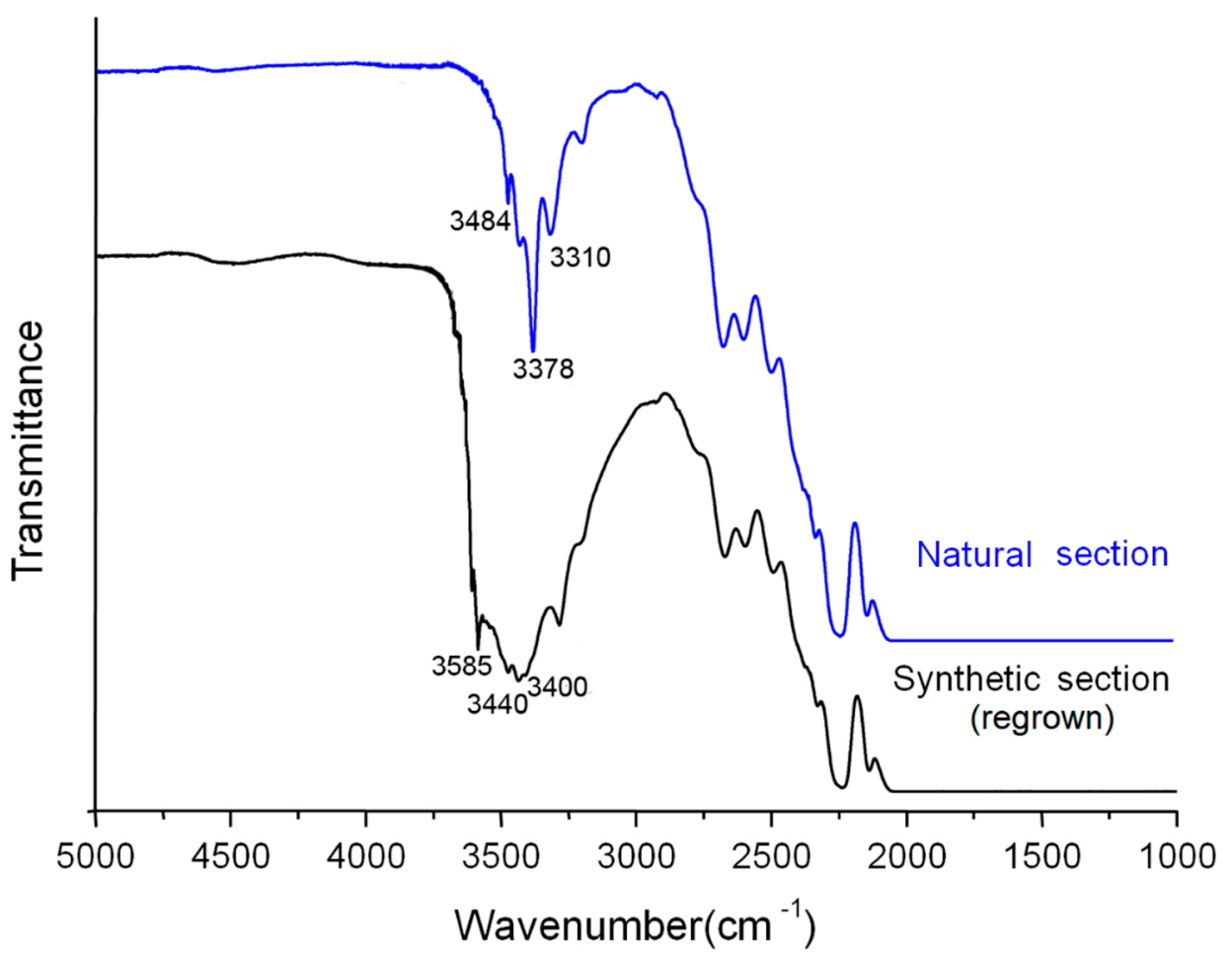

Figure 4. Infrared spectra of natural section and synthetic section of the regrown quartz crystal.

\section{Discussion}

The synthetic layer of regrown quartz crystal consists of $\alpha$-quartz, while quartz can transfer from $\alpha$-quartz to $\beta$-quartz at $573{ }^{\circ} \mathrm{C}$. Therefore, the crystallization temperature of the synthetic regrown quartz layer is usually under $573{ }^{\circ} \mathrm{C}[2-4,22-25]$. The growing process of hydrothermally synthetic quartz is accomplished in an autoclave. Melted quartz or broken pieces of natural vein quartz as raw material for $\mathrm{SiO}_{2}$ source and alkaline solution (containing $\mathrm{K}^{+}, \mathrm{Na}^{+}, \mathrm{Li}^{+}$, etc.) as mineralizer are used during the process. The interior of autoclave can be divided into two parts which are raw material dissolution zone and the crystallization zone, with the temperature from $300{ }^{\circ} \mathrm{C}$ to $380{ }^{\circ} \mathrm{C}$, the temperature of the dissolution zone is relatively higher) and the pressure from $1.1 \sim 1.6 \times 10^{8} \mathrm{~Pa}$ [2-7].

Due to the closed environment and the controlled conditions in the autoclave, the forming environment of synthetic quartz was relatively uniform and stable, which can explain its fewer defects and lower porosity. However, natural quartz formed in an open natural environment so that the temperature, pressure, composition of ore-forming fluid and other factors were in constant change, which resulted in the internal features of gasliquid inclusion, mineral inclusion, negative crystal, fracture, colored tape, etc. For the regrown quartz crystal, the synthetic quartz layer grew around the surface of natural quartz. Hence, it has similar inclusions with those in the natural quartz under a microscope, making it easy to be confused. Nevertheless, the difference on the defect amount and porosity of the natural section and the synthetic section of regrown quartz crystal, which are caused by the different forming environment, can be visually displayed in the 3D image of microstructure characteristics. There are many micron- to millimeter-sized pores in the natural section or on the interface of the natural and synthetic section, while the porosity of the synthetic section is much lower.

The infrared spectra of the two sections of regrown quartz crystal show a significant distinction on absorption peaks in the $3300-3600 \mathrm{~cm}^{-1}$ range, which are mainly related to the $\mathrm{OH}$ group which comes from the ore-forming fluid or solution. Natural quartz and synthetic quartz differ in the temperature and the component of ore-forming fluid during crystallization. The existence state of $\mathrm{OH}$ groups influenced by alkali cations (e.g., $\mathrm{K}^{+}, \mathrm{Na}^{+}$, $\mathrm{Li}^{+}$) of growth solution in the synthetic quartz section leads to different infrared absorption 
characteristics from those in the natural quartz section. Therefore, it can be inferred that the difference in the forming condition has an influence on the existence state of $\mathrm{OH}$ groups in the structure of $\mathrm{SiO}_{2}$, which leads to the different absorption characteristics of the natural and synthetic sections of regrown quartz crystals.

\section{Conclusions}

Regrown quartz crystals on the Chinese jewelry market consist of the natural section and the synthetic section by hydrothermal synthetic technique. They have similar gemological properties with those of natural quartz, which has brought challenges to gem identification and also new questions to scientific research. However, they display different microstructure and spectral characteristics between the two sections in the regrown quartz crystal. The natural section has a higher porosity and there are also many micron- to millimeter-sized pores on the interface of the two sections. The differences on the absorption peaks in the $3300-3600 \mathrm{~cm}^{-1}$ range of infrared spectra are mainly attributed to the existence state of $\mathrm{OH}$ groups.

Microstructure and spectral characteristics indicate different forming conditions between natural quartz and synthetic quartz. For regrown quartz crystals, the relatively stable forming environment during synthetic process leads to a lower porosity and the different forming solution can result in the change of the existence state of $\mathrm{OH}$ groups compared with natural quartz.

Investigation results in this study can provide reference not only for regrown quartz crystals identification but also the discussion on the crystal nucleation, growth, and dissolution process of hydrothermally synthetic gemstone on the natural ones. In the future, with the upgrading and the development of regrowth techniques, it is foreseeable that more regrown gemstones with higher quality will emerge on the jewelry market and deserve further study.

Author Contributions: Investigation, D.Z., H.D. and J.L.; writing—original draft preparation, D.Z.; writing-review and editing, D.Z. and T.L.; visualization, D.Z. and S.C.; supervision, T.L., Z.S. and J.Z.; project administration, D.Z.; funding acquisition, D.Z. and T.L. All authors have read and agreed to the published version of the manuscript.

Funding: This research was funded by the National Science Foundation of China (42073008) and by NGTC Scientific Research Fund (NGTC20200903).

Data Availability Statement: Data available on request due to restrictions privacy. The data provided in this study can be obtained at the request of the corresponding author. As the data needs further research, the data is currently not publicly available.

Acknowledgments: Thanks are given to Qinfang Fang of China University of Geosciences (Beijing) for their assistance in the microstructure measurement. We are also grateful to all reviewers and editors for their constructive and helpful comments, which significantly improved the manuscript.

Conflicts of Interest: The authors declare no conflict of interest.

\section{References}

1. Wooster, N.; Wooster, W.A. Preparation of synthetic quartz. Nature 1946, 157, 297. [CrossRef]

2. Heaney, P.J.; Prewitt, C.T.; Gibbs, G.V. Silica: Physical Behavior, Geochemistry and Materials Applications; Mineralogical Society of America: Blacksburg, VA, USA, 1994.

3. Zhong, W.Z. Synthetic Quartz; Science Press: Beijing, China, 1983.

4. He, X.M.; Shen, C.Q. Artificial Synthesis Technology of Gemstones, 2nd ed.; Chemical Industrial Press: Beijing, China, 2010.

5. Balitsky, V.S.; Lu, T.J.; Rossman, G.R.; Makhina, I.B.; Marin, A.A.; Shigley, J.E.; Elen, S.; Dorogovin, B.A. Russian Synthetic Ametrine. Gems Gemol. 1999, 35, 122-134. [CrossRef]

6. Balitsky, V.S.; Makhina, I.B.; Marina, E.A.; Rossman, G.R.; Lu, T.J.; Shigley, J.E. Growth and characteristics of some new varieties of coloured quartz single crystals. High Press. Res. Int. J. 2001, 20, 219-227. [CrossRef]

7. Balitsky, V.S.; Kurashige, M.; Balitskaya, L.V.; Twasaki, H. Kinetics of dissolution and state of silica in hydrothermal solutions of $\mathrm{Na}_{2} \mathrm{CO}_{3}$ and $\mathrm{NaOH}$, and accelerated method for the quartz crystal characterization against growth rate. J. Cryst. Growth 2002, 237-239, 828-832. [CrossRef] 
8. Ng-Pooresatien, N. Synthetic rock crystal quartz bangle with unusual inclusions. Gems Gemol. 2015, 51, 439-440.

9. Skalwold, E.A. Micro-world: Synthetic quartz: A designer inclusion specimen. Gems Gemol. 2016, 52, 425-426.

10. Clifford, J.H.; Klipov, V.A. A marriage of science and art: Creating quartz specimens in the laboratory. Rocks Miner. 2015, 90, 379-385. [CrossRef]

11. Dai, H.R.; Zhou, D.Y.; Song, Z.H.; Su, J.; Li, H.B.; Lu, T.J.; Ma, Y.W. Synthetic rock crystal clusters on the Chinese Market. J. Gemmol. 2020, 37, 354-356. [CrossRef]

12. Xie, P.H. The discrimination of surface accreting compound crystal druse from natural crystal druse. Yunnan Geol. 2008, 27, 434-436.

13. Wood, D.L. Infrared absorption of defects in quartz. J. Phys. Chem. Solids 1960, 13, 326-336. [CrossRef]

14. Kats, A. Hydrogen in alpha quartz. Philips Res. Rep. 1962, 17, 133-195; discussion 201-279.

15. Dodd, D.M.; Fraser, D.B. The $3000-3900 \mathrm{~cm}^{-1}$ absorption bands and anelasticity in crystalline $\alpha$-quartz. J. Phys. Chem. Solids 1965, 26, 673-686. [CrossRef]

16. Staats, P.A.; Kopp, O.C. Studies on the origin of the $3400 \mathrm{~cm}^{-1}$ region infrared bands of synthetic and natural $\alpha$-quartz. J. Phys. Chem. Solids 1974, 35, 1029-1033. [CrossRef]

17. Krefft, G.B. Effects of high-temperatrue electrolysis on the coloration characteristics and $\mathrm{OH}$ absorption bands in alpha quartz. Radiat. Eff. 1975, 26, 249-259. [CrossRef]

18. Aines, R.D.; Rossman, G.R. Water in minerals? A peak in the infrared. J. Geophys. Res. Solid Earth 1984, 89, 4059-4071. [CrossRef]

19. Aines, R.D.; Kirby, S.H.; Rossman, G.R. Hydrogen speciation in synthetic quartz. Phys. Chem. Miner. 1984, 11, 204-212. [CrossRef]

20. Cao, P.; Yu, L.; Zu, E.D. Study on the near infrared spectrum of natural crystals and synthetic crystals by hydrothermal method. J. Light Scatt. 2017, 29, 177-180.

21. Stalder, R.; Potrafke, A.; Billström, K. OH defects in quartz as monitor for igneous, metamorphic, and sedimentary processes. Am. Mineral. 2017, 102, 1832-1842. [CrossRef]

22. Moarefvand, A.; Fauconnier, J.; Gasc, J.; Deldicque, D.; Labrousse, L.; Schubnel, A. Experimental study of the effect of stress on $\alpha \rightarrow \beta$ quartz transformation at lower continental crust pressure and temperature. Geophys. Res. Abstr. 2019, $21,1$.

23. Hu, Q.Y.; Shu, J.F.; Yang, W.G.; Park, C.; Chen, M.W.; Fujita, T.; Mao, H.K.; Sheng, H.W. Stability limits and transformation pathways of $\alpha$-quartz under high pressure. Phys. Rev. B 2017, 95, 104-112. [CrossRef]

24. Karunadasa, K.S.P.; Manoratne, C.H.; Pitawala, H.M.T.G.A.; Rajapakse, R.M.G. The composition, unit cell parameters and microstructure of quartz during phase transformation from $\alpha$ to $\beta$ as examined by in-situ high-temperature $X$-ray powder diffraction. J. Phys. Chem. Solids 2018, 117, 131-138. [CrossRef]

25. Lawn, B.R.; Marshall, D.B.; Raj, R.; Hirth, G.; Page, T.F.; Yeomans, J. Precipitous weakening of quartz at the $\alpha-\beta$ phase inversion. J. Am. Ceram. Soc. 2021, 104, 23-26. [CrossRef] 